Revista de Contabilidade e Organizações (2019) n. temático

Fraudes e Corrupção: o que Contabilidade e Organizações têm a dizer? 64-74

Revista de

Contabilidade e

Organizações

www.rco.usp.br
DOI: http://dx.doi.org/10.11606/issn.1982-6486.rco.2019.158324
Journal of

Accounting and

Organizations

www.rco.usp.br

\title{
Criando dificuldades para vender facilidades: corrupção, burocracia e crescimento corporativo no Mercosul
}

Creating difficulties to sell facilities: corruption, bureaucracy and corporate growth in Mercosur

Lauro Vinício de Almeida Lima ${ }^{\mathrm{a}}$, Maria Audenora Rufino ${ }^{\mathrm{ab}}$, Márcia Reis Machado

aniversidade Federal da Paraiba

${ }^{b}$ Universidade Federal do Sergipe

Palavras-chave

Burocracia.

Corrupção.

Crescimento econômico.

Teoria da Graxa sobre Rodas.

Mercosul.

\begin{abstract}
Resumo
A pesquisa teve como escopo investigar, nos países do Mercosul, o reflexo da sinergia entre a dificuldade de realização de negócios e a percepção da corrupção do setor público no crescimento econômico e financeiro das empresas. A amostra foi composta por 8 países integrantes do Mercosul, entre os anos de 2010 a 2017, com um total de 655 empresas de diversos setores e 4.648 observações. Com base na Teoria da Graxa sobre Rodas, o estudo levou em consideração que a corrupção pode favorecer o crescimento econômico das empresas, à medida que desate as amarras da burocracia e reduza os custos transacionais das empresas. Os resultados encontrados conduzem ao entendimento de que a associação sinérgica entre a percepção da corrupção e a dificuldade de realizações de negócios nos países do Mercosul favorece o crescimento econômico das empresas em tais países. O efeito sinérgico positivo é direcionado, preponderantemente, para as grandes empresas, em função de maiores condições financeiras de arcar com os custos da corrupção. As evidências empíricas encontradas acrescentam novas centelhas para o constructo argumentativo no qual se pauta a Teoria da Graxa sobre Rodas.
\end{abstract}

Keywords

Bureaucracy.

Corruption.

Economic growth

Grease Theory on Wheels.

Mercosul.
Informações do artigo

Recebido: 25 de maio de 2019

Aceito: 13 de novembro de 2019

Publicado: 28 de novembro de 2019

\begin{abstract}
This research aims to investigate the synergy between the difficulty of conducting business and the perception of public sector corruption in the growth of companies, in the Mercosur countries. The sample consisted of 8 Mercosur member countries, between 2010 and 2017, with a total of 655 companies from several sectors and 4,648 observations. Based on the Wheel Grease Theory, the study took into account that corruption can favor the economic growth of companies as they untie bureaucracy and reduce the transactional costs of companies. The results found lead to the understanding that a greater synergy between the perception of corruption and the difficulty of doing business in Mercosur countries favors the economic growth of companies in those countries. The empirical evidence found adds new sparks to the argumentative construct in which the Grease Wheel Theory is based.
\end{abstract}

\section{Implicações práticas}

Os resultados podem interessar a órgãos de fiscalização, investidores e gestores de empresas, ao argumentar que uma maior sinergia entre as exigências burocráticas, entendidas como a dificuldade de realização de negócios, e a percepção de corrupção do país, apresentam efeitos positivos no crescimento das organizações em países em desenvolvimento.

\footnotetext{
Autor correspondente: Tel. (83) 3216-7285

E-mail: 1vinicio2@gmail.com (L. V. de A. Lima); maryaudenora@hotmail.com (M. A. Rufino); marciareism@hotmail.com(M. R. Mahcado) Universidade Federal da Paraíba, Centro de Ciências Sociais Aplicadas - Campus I. Via Expressa Padre Zé, 289 - Castelo Branco III, João Pessoa/PB - 58059900, Brasil
} 


\section{INTRODUÇÃO}

A burocracia e a corrupção parecem andar de mãos dadas. A dificuldade obstaculizada pela burocracia provoca desinteresse pelo investimento, em razão dos altos custos transacionais gerados pela complexidade das exigências normativas impostas às empresas. Paralelamente, a corrupção surge, fornecendo meios ágeis para concretização de negócios em ambientes burocráticos e favorecendo àqueles que a utilizam como forma de burlar as exigências normativas. Assim, é possível que o crescimento econômico das empresas seja estimulado, por intermédio da associação entre a burocracia e a corrupção, em países onde ocorra uma maior sinergia entre elas.

$\mathrm{O}$ ambiente de descrédito social e impunidade, observado pelos participantes de um mercado supervisionado por um Governo corrompível, traz pesos e contrapesos descompassados com a razoabilidade ética. Uma percepção de corrupção generalizada pela sociedade pode induzir os gestores das empresas a ultrapassarem os limites da moralidade, tirando proveito da desordem social para obter maiores retornos, ao driblar as exigências do sistema normativo e libertar-se das amarras da burocracia (Lopes Júnior, Cãmara, Rocha \& Brasil, 2018).

A racionalidade dos agentes econômicos em um ambiente global competitivo induz à compreensão que os fornecedores de capital irão canalizar os investimentos para projetos que proporcionem maiores retornos, adotando estratégias financeiras que majorem os lucros. Assim, ao ponderar riscos e retornos, os investidores apostarão em projetos que otimizem a performance e o retorno. Isso porque os negócios, situados em um ambiente no qual a corrupção suavize as amarras impostas pela burocracia, captariam mais investimentos. $\mathrm{O}$ efeito ocorreria porque há um entendimento que esses investimentos atenderão as expectativas do mercado, ao proporcionarem retornos em patamares mais altos, dado que uma associação sinérgica entre burocracia e corrupção fará com que as empresas se beneficiem com maiores facilidades (Antunes \& Procianoy, 2003; Fama \& French, 2006; Fortunato, Funchal, \& Motta, 2012).

Os reflexos da corrupção foram estudados nesta pesquisa a partir de duas principais perspectivas: (i) a corrupção como um fator que leva a redução do crescimento da empresa, principalmente, pela perda da credibilidade pelos investidores atuais ou potenciais da empresa; e (ii) a corrupção como resposta a problemas burocráticos determinados pelo ambiente, que conduzem à dificuldade de realização de negócios. Na primeira, a corrupção seria um desincentivo ao investimento, desembocando na redução do crescimento e da produtividade, atuando como uma "areia nas engrenagens" das empresas (Vu, Tran, Nguyen, \& Lim, 2018). Enquanto a segunda, aponta a possibilidade de efeitos benéficos da corrupção, sendo mais intensos em um ambiente onde as instituições funcionam mal e o excesso de burocracia seja um fator limitante de eficiência (Aidt, 2003; Vial \& Hanoteau, 2010; Dreher \& Gassebner, 2013; Kato \& Sato, 2015).

Os efeitos positivos da corrupção discorridos na literatura estão relacionados como meio de contornar a ineficiência organizacional decorrente da burocracia (Lopes Júnior, Cãmara, Rocha \& Brasil, 2018). Sob essa acepção, a corrupção seria menos prejudicial à eficiência em países onde as instituições de monitoramento e controle fossem menos eficazes. Podendo apresentar uma associação positiva com a eficiência em países onde as instituições são extremamente ineficazes (Méon \& Weill, 2010).

Existem evidências empíricas que apontam a existência de um lado positivo da corrupção para empresas, como ocorreu na análise comparativa entre corrupção, crescimento e investimento, indicando uma relação positiva entre o crescimento e a corrupção em países industrializados do leste asiático, como a China e a Indonésia (Rock \& Bonnett , 2004). Assim como, a corrupção teria efeito positivo sobre o valor adicionado bruto por trabalhador e sobre a relação capital e mão de obra em setores de produção regulamentados na Índia (Kato \& Sato, 2015); e, também, quando se concluiu que a corrupção facilita a entrada de empresas em economias altamente reguladas (Dreher \& Gassebner, 2013).

Portanto, é possível que uma maior sinergia entre a burocracia e a corrupção permita às empresas alcançarem seus objetivos, por meio da superação de exigências normativas pouco claras ou complexas. Como resultado, as empresas poderiam economizar tempo e conduzir suas atividades de negócios mais rapidamente, ou seja, "engraxar as rodas" do desenvolvimento corporativo, promovendo, assim, o seu crescimento financeiro e econômico (Aidt, 2003; Vial \& Hanoteau, 2010).

Nesse contexto, esta pesquisa busca aprofundar-se nessa discussão, com o argumento de que uma maior sinergia entre as exigências burocráticas - entendidas como a dificuldade de realização de negócios - e a percepção de corrupção do país pode trazer efeitos positivos ao crescimento das organizações em países emergentes, como os países integrantes do Mercosul. Diante disso, o presente estudo busca responder o seguinte questionamento: qual o efeito da sinergia entre a dificuldade de realização de negócios e a percepção de corrupção no crescimento econômico e financeiro das empresas dos países integrantes do Mercosul? 
O contributo teórico é analisar, à luz da Teoria da Graxa sobre Rodas e da Teoria dos Custos de Transação, se a atuação conjunta entre a burocracia, proveniente da dificuldade de realização de negócios, e a corrupção, pode contribuir para o crescimento econômico das empresas. Apesar da burocracia ser vista como um elemento limitante a atos de oportunismo e que atentem aos anseios sociais, este estudo, leva em consideração que o excesso de burocracia pode gerar um efeito inverso ao esperado. Ao invés de mitigar a corrupção, torna-se um fator agregado a ela, podendo gerar crescimento econômico e financeiro anormal nas empresas.

Busca-se expandir os limites dos estudos relacionados ao comportamento organizacional, ligados ao crescimento econômico, para propor explicações mais complexas sobre o ambiente empresarial, nos blocos econômicos compostos por países em desenvolvimento, diante da burocracia e da corrupção.

Para responder tais inquietações, os aspectos metodológicos se pautaram em uma pesquisa teóricoempírica, utilizando dados econômico-financeiros das empresas não financeiras de capital aberto situadas no Mercosul e atributos caraterísticos dos países, como nível de percepção de corrupção e nível de burocracia. Os países utilizados para compor a amostra foram Argentina, Bolívia, Brasil, Chile, Colômbia, Equador, Peru e Venezuela, no período de 2010 a 2017. O modelo econométrico consistiu em um painel desbalanceado estimado com efeitos fixos. As principais variáveis foram: a resultante do vetor comum entre o índice de dificuldade de realização de negócios e o índice de percepção da corrupção (variável independente) e um fator comum às variáveis que mediram o crescimento das empresas.

Utilizando tais aspectos metodológicos, diante da lacuna identificada e da importância dessa discussão em um contexto econômico e social amplo, os resultados indicam que as empresas apresentaram um maior crescimento econômico em países com maior sinergia entre a percepção de corrupção e a dificuldade de realização de negócio. Considerando o contexto das empresas situadas nos países do Mercosul os resultados indicam que a Teoria da Graxa sobre as Rodas explica melhor o comportamento do crescimento das empresas frente à corrupção e à burocracia.

\section{PLATAFORMA TEÓRICA}

A teoria dos custos de transação desenvolvida por Coase (1937) explica as diversas relações, internas e externas, das empresas no mercado, como um arranjo de vínculos contratuais, dos quais incorrem custos para gerenciamento das transações com a negociação e as cláusulas de garantia de adimplemento.

Nesse baluarte, Williamson (1973) aprofundou o estudo sobre a teoria dos custos de transação explicando que, na concretização das transações entre partes, há infortúnios intrínsecos resultantes de dois componentes inevitáveis. O primeiro diz respeito ao comportamento das partes, haja vista que a teoria parte do pressuposto da racionalidade limitada dos indivíduos, levando-os à propensão de adoção de comportamentos oportunistas. E o segundo, decorre da falta de conhecimento pleno dos indivíduos sobre o ambiente, impossibilitando-o de alcançar uma solução que maximize a eficiência. Assim, surgem custos de transação, como gastos com planejamento, adaptação e monitoramento entre as partes envolvidas, visando a execução dos contratos de forma satisfatória e compatível com o objetivo firmado.

Os custos de transação ganham relevo na análise da elaboração e negociação dos contratos, nos conflitos entre a gestão e a propriedade, organização das atividades, monitoramento do desempenho e, principalmente, na relação entre as empresas e o setor público. Neste aspecto, a corrupção pode surgir como um fator mitigador dos vínculos contratuais, reduzindo os custos transacionais entre as empresas e o governo.

Entende-se por corrupção, o desvio moral ou social motivado pelo autobenefício do praticante, seja na modalidade ativa ou passiva (Silva, Braga \& Laurencel, 2009). Normalmente, o seu conceito está ligado à Administração Pública, pelo desvio de verbas públicas, uso de bens públicos em proveito privado, suborno, tráfico de influência, fraude e outros. Entretanto, a corrupção pode se estender para a iniciativa privada, em função da sensação de desordem e baixo risco punitivo vivenciado pela sociedade, haja vista que os agentes públicos, que deveriam dar exemplo, estão envolvidos com comportamentos legalmente, eticamente, reprováveis (Silva, Braga \& Laurencel, 2009).

As consequências econômicas da corrupção são conhecidas, podendo afetar uma ampla gama de fenômenos sociais e econômicos (por exemplo, crescimento econômico, sistemas de saúde públicos e educação); porém existem controvérsias sobre os efeitos da corrupção de um país sobre o desempenho das empresas. Estudos apontam que os efeitos podem refletir as características do país e que as economias emergentes sentem mais intensamente os efeitos da corrupção. 
Lau, Demir e Bilgin (2013) investigaram como a corrupção corporativa, baseada em experiência, influencia a volatilidade do mercado de ações em 14 mercados emergentes, e constataram que os países com maior corrupção tendem a ter mercados acionários menos voláteis, porque reduziria a incerteza sobre o desempenho, mesmo após controlar as características das empresas, como liquidez e maturidade do mercado e outras variáveis econômicas.

O interesse da comunidade científica pela corrupção tem crescido ao longo das últimas décadas. Teoricamente, o efeito da corrupção sobre desempenho das empresas não pode ser explicado ou previsto por uma única teoria existente (Vu, Tran, Nguyen, \& Lim, 2018). As duas correntes teóricas mais utilizadas para explicar o efeito da corrupção sobre as organizações são: (a) areia nas rodas - Sand the Wheel - que critica a corrupção e busca evidenciar os obstáculos e prejuízos causados por ela; e (b) a graxa sobre rodas - Grease the Wheel - que apresenta os resultados benéficos que a corrupção possui na economia.

A corrupção e a ineficiência da burocracia têm sido frequentemente consideradas como dois limitantes do desenvolvimento econômico e do desempenho das organizações, porém a ineficiência da burocracia tem sido apontada como mais acentuada. Nesse sentido, o argumento da "graxa sobre rodas" se insere como uma resposta à ineficiência burocrática, reduzindo o tempo gasto com espera e os custos da lentidão.

A ideia predominante sobre a relação entre a corrupção e o crescimento das empresas é que a corrupção exerce uma influência negativa no crescimento, devido à instabilidade política e as relações curtas ou pontuais entre empresas e agentes. No entanto, algumas pesquisas defendem que a corrupção propicia um efeito marginal positivo na eficiência em países com governo corrupto (Méon \& Weill, 2010). O argumento da "graxa sobre rodas" postula que uma burocracia ineficiente constitui um grande impedimento à atividade econômica, e que alguma "velocidade" ou "graxa" pode ajudar a contornar esse impedimento (Aidt, 2003).

Estudos testaram os benefícios e malefícios da corrupção em diversos cenários. Vial e Hanoteau (2010), ao avaliarem o impacto da corrupção no nível da indústria e no crescimento da produtividade, descobriram que a corrupção, como subornos e pagamentos de impostos indiretos, tem um efeito positivo no crescimento individual das indústrias. Kato e Sato (2015) investigaram se a corrupção "lubrifica as engrenagens" das burocracias e melhora o desempenho econômico, encontrando resultados condizentes com a perspectiva da Teoria da Graxa sobre Rodas.

Dreher e Gassebner (2013) investigaram se a corrupção pode "lubrificar as engrenagens" econômicas, e encontraram que a corrupção reduz o impacto negativo das regulamentações sobre o empreendedorismo em economias altamente reguladas. Complementarmente, Goedhuys, Mohnen e Taha (2016) exploraram o efeito dos obstáculos institucionais e da corrupção no comportamento inovador das empresas, verificando que a corrupção tem um efeito negativo direto sobre a probabilidade de uma empresa ser inovadora, mas um efeito positivo quando interage com obstáculos institucionais.

Portanto, diante dos argumentos conflitantes que a corrupção pode ser a areia sobre as engrenagens econômicas (negativo) ou a graxa sobre as suas rodas (positivo), seguido pelas evidências encontradas em várias partes do mundo, é importante aprofundar o estudo sobre o tema, ante a possibilidade de a corrupção trazer malefícios ou benefícios marginais para as empresas.

\section{METODOLOGIA}

A pesquisa abrangeu as empresas não financeiras de capital aberto sediadas em países do Mercosul. O Mercosul foi escolhido por ser um bloco que guarda um projeto econômico e político-estratégico, inspirado no modelo europeu, mas conservando sua própria originalidade, em razão de ser composto por países em desenvolvimento com singular convergência cultural e similaridade social, econômica e política. A comparabilidade das empresas dentro do bloco é possível por estarem inseridas em uma zona de livre comércio que foi convertida em uma união aduaneira, possuindo uma tarifa externa comum.

Os países utilizados para compor a amostra foram: Argentina, Bolívia, Brasil, Chile, Colômbia, Equador, Peru e Venezuela. Por falta de acesso aos dados das empresas de capital aberto da Guiana, Suriname, Uruguai e Paraguai, estas, não foram incluídas na amostra. As empresas do setor financeiro e seguros foram excluídas devido a regulamentação especial a que são submetidas e pela peculiaridade de sua estrutura de capital. Tais fatores poderiam enviesar a análise das relações e possíveis influências relacionadas às variáveis estudadas. 
As demonstrações contábeis das empresas, de 2010 a 2017, foram captadas do banco de dados da Thomson Reuters Eikon ${ }^{\circledR}$, utilizando o dólar como moeda de referência. O ano de 2010 foi escolhido porque entre 2008 e 2009 ocorreu uma crise financeira internacional desencadeada pela falência do banco americano Lehman Brothers, gerando um efeito cascata em outras instituições financeiras que, também, foram levadas à falência. Este processo ficou conhecido como "crise dos subprimes" (Feldkircher, 2014). A crise financeira mundial pode ter afetado os resultados reportados pelas empresas do Mercosul, com consequências no crescimento econômico-financeiro das empresas naquele período.

As informações relativas aos índices de dificuldade para realização de negócios e de percepção da corrupção do setor público, por país e ano, foram coletados a partir dos dados disponíveis no site The World Bank e Transparency International, respectivamente.

A Equação 1 foi utilizada para estimar a influência do fator comum (sinergia), decorrente da dificuldade de realização de negócios e da percepção da corrupção no setor público, no crescimento econômico e financeiro das empresas dos países do Mercosul.

$$
\text { Crescit }=\alpha_{0}+\alpha_{1} F B C_{p t}+\alpha_{2} \operatorname{Rec}_{i t}+\alpha_{3} R O A_{i t}+\alpha_{4} \text { End }_{i t-1}+\alpha_{5} \operatorname{Tam}_{i t-1}+\alpha_{6} G_{P I B}+\varepsilon
$$

Em que:

Crescit: é o um vetor de crescimento, contabilmente captado, da empresa $i$ no tempo $t$, comum às seguintes medidas: variação dos ativos totais $(\Delta \mathrm{AT})$, variação do ativo imobilizado sobre os ativos totais ( $\Delta$ Imob), variação do patrimônio líquido sobre os ativos totais $(\Delta \mathrm{PL})$, variação das receitas líquidas sobre os ativos totais $(\Delta \mathrm{Rec}) \mathrm{e}$ variação dos fluxos de caixa operacional sobre os ativos totais $(\Delta \mathrm{FCO})$, todas da empresa $i$ no período $t$ em relação ao período $t-1$;

$F B C_{p t}$ : é um vetor comum à burocracia e corrupção. O índice de dificuldade de realização de negócios (Burocracia) foi calculado pela diferença entre 100 e o índice de facilidade de realização de negócios divulgado pelo World Bank, no país $p$ no período $t$, divido por 100, para que o entendimento do índice de dificuldade para realização de negócios seja analisado na escala de zero (muito fácil) a 1 (muito difícil). Já o índice de percepção de corrupção no setor público (Corrupção) foi calculado pela diferença entre 100 pontos e o índice de percepção divulgado pelo Transparency International, no país $p$ no período $t$, dividindo o resultado por 100, para que o entendimento do índice de percepção da corrupção seja analisado na escala de zero (altamente íntegro) a 1 (altamente corrupto). Assim, foi possível obter a sinergia entre as duas variáveis, Burocracia e Corrupção, em apenas uma, $F B C$ - que contém a associação sinérgica entre a dificuldade de realização de negócios e a percepção da corrupção;

$R e c_{i t}$ : é a receita da empresa, calculado pelo logaritmo natural da receita líquida da empresa $i$ no período $t$;

$R O A_{i t}$ : é o Retorno sobre os Ativos, Return On Asset (ROA), calculado pela divisão do lucro líquido sobre o ativo total da empresa $i$ no período $t$-1;

End $_{i t-1}$ : é o endividamento da empresa, calculado pelo total de capital de terceiros (passivo de curto e longo prazo) sobre o ativo total da empresa $i$ no período $t$;

$\operatorname{Tam}_{i t-1}$ : Tamanho da empresa, calculado pelo logaritmo natural do ativo total da empresa $i$ no período $t-1$;

$G P I B_{p t-1}$ : é o crescimento anual do Produto Interno Bruto (PIB) per capita anual do país $p$ no período $t-1$;

$\alpha_{0} \ldots \alpha_{6}$ : são os parâmetros estimados;

$\varepsilon$ : é o resíduo da regressão.

As variáveis Cresc, vetor de crescimento econômico e financeiro das empresas, e $F B C$, vetor de corrupção e burocracia, foram calculados por meio da técnica multivariada de análise fatorial. O objetivo do uso desta técnica foi descrever as relações de covariância entre as variáveis em um fator comum. Quanto maior os vetores Cresc e $F B C$, maior será o crescimento da empresa e a associação sinérgica entre burocracia e corrupção, respectivamente.

As variáveis de controle receita $(R e c)$ e tamanho $(\mathrm{Tam})$ foram incluídas para controlar as peculiaridades relacionadas a magnitude da empresa, haja vista que empresas com grandes receitas e tamanho, em termos percentuais, não teriam a mesma capacidade de crescer, proporcionalmente, quando comparadas com empresas menores ou que auferem baixas receitas. O endividamento $(E n d)$ foi incluído para controlar o efeito do capital de terceiros no crescimento das empresas, pois as empresas podem alavancar suas atividades operacionais com os recursos de terceiros. E o crescimento anual do Produto Interno Bruto (GPIB) teve o propósito de controlar os efeitos do crescimento econômico geral do país nas empresas. 
Os dados utilizados na pesquisa foram trabalhados em uma regressão de painel desbalanceado, visando ampliar ao máximo a quantidade de observações, referentes aos exercícios de 2010 a 2017. Utilizou-se as principais técnicas de dados em painel para verificação do modelo mais adequado para o tratamento dos dados, entre o modelo irrestrito pooled, o modelo restrito de efeitos fixos e o modelo restrito de efeitos aleatórios, por intermédio dos testes de Chow, Hausman e Breusch-Pagan. Também foram aplicados os testes de Wooldridge e Wald modificado para dados em painel para observar, respectivamente, a autocorrelação e a heterocedasticidade dos dados (Fávero, 2013).

\section{RESULTADOS}

A amostra contendo 665 empresas, relativas a 8 países do Mercosul, entre os anos de 2010 e 2017, está quantitativamente retratada na Tabela 1. Em relação as variáveis Variação do Ativo Total, Variação do Imobilizado, Variação do Patrimônio Líquido e Variação da Receita os resultados indicam que, em média, houve aumento dos valores ao longo dos períodos. Enquanto a variável Variação do Fluxo de Caixa Operacional demonstra, em média, uma redução dos fluxos de caixa operacional de 2010 a 2017. Contudo, o desvio padrão de aproximadamente 3,40 sugere que o valor negativo da média pode ser reflexo de um grupo pontual de empresa com fluxos de caixa negativo, e não uma característica persistente da amostra. Comparando a média da variável Burocracia com a média da variável Corrupção, verifica-se que, em média, a percepção de corrupção é maior do que a dificuldade de realização de negócio.

Tabela 1. Estatística descritiva das variáveis

\begin{tabular}{lccccc}
\hline \multicolumn{1}{c}{ Variáveis } & Média & Mediana & $\begin{array}{c}\text { Desvio } \\
\text { Padrão }\end{array}$ & Mínimo & Máximo \\
\hline Variação do Ativo Total - $\Delta \mathrm{AT}$ & 0,0656 & 0,2611 & 0,2960 & $-0,4280$ & 1,7848 \\
Variação do Imobilizado - $\Delta$ Imob & 0,0198 & 0 & 0,6439 & -1 & 4,4104 \\
Variação do Patrimônio Líquido - $\Delta \mathrm{PL}$ & 0,0784 & 0,0091 & 0,4922 & $-0,7407$ & 3,1265 \\
Variação da Receita - $\Delta$ Rec & 0,0773 & 0,0343 & 0,3745 & $-0,7362$ & 2,1717 \\
Variação do Fluxo de Caixa Operacional - $\Delta \mathrm{FCO}$ & $-0,0315$ & $-0,1248$ & 3,4036 & $-13,5302$ & 20,6152 \\
Burocracia & 0,3848 & 0,4122 & 0,0752 & 0,2893 & 0,6833 \\
Corrupção (índice de percepção) & 0,5532 & 0,62 & 0,1439 & 0,27 & 0,83 \\
Receita - Rec & 19,2291 & 19,4304 & 2,2751 & 5,7179 & 25,6463 \\
Retorno do Ativo - ROA & 0,0393 & 0,0369 & 0,1073 & $-2,2650$ & 1,0547 \\
Endividamento - End & 0,5053 & 0,5145 & 0,2124 & $-0,0607$ & 0,9976 \\
Tamanho - Tam & 19,8738 & 19,937 & 2,0546 & 10,096 & 26,5125 \\
GPIB & 1,7707 & 1,88 & 3,0031 & $-5,209$ & 8,991 \\
\hline Empresas & & & 665 & & \\
Observações & & & 4648 & & \\
\hline
\end{tabular}

Fonte: Elaborada pelos autores.

Nota: As variáveis $\Delta \mathrm{AT}, \Delta \mathrm{Imob}, \Delta \mathrm{PL}, \Delta \mathrm{Rec}$ e $\Delta \mathrm{FCO}$ foram winsorizadas em $0,5 \%$, em razão do alto desvio padrão encontrado, inicialmente, nos dados.

As variáveis Burocracia e Corrupção são medidas a nível país e período. A estatística descritiva da variável Burocracia varia de 0,2893 a 0,6833 entre os países integrantes da amostra, o que indica diferença no nível de burocracia entre os países. O desvio padrão de 0,0752 indica que a discrepância não é grande. O resultado do desvio padrão dessa variável é explicado pela baixa variabilidade do índice de um período para outro. Visto que, o índice varia mais entre os países do que de período para período.

A variável corrupção varia de 0,27 a 0,83 , apresenta média de 0,5532 e desvio padrão de 0,1439 , tal resultado indica que a percepção de corrupção varia entre países e/ou períodos. Comparando o comportamento das variáveis Burocracia e Corrupção, a última apresenta oscilação maior entre os países e/ou períodos, o que denota que a corrupção é percebida em diferentes magnitudes entre os países.

Na Tabela 2 é apresentada a correlação de Pearson entre as cinco dimensões de crescimento utilizadas no estudo para calcular o fator de crescimento econômico e financeiro utilizado como variável dependente na Equação 1. E na Tabela 3 apresenta-se a matriz de correlação de Pearson entre as variáveis métricas incluídas na análise da regressão da Equação 1. 
Tabela 2. Correlação de Pearson

\begin{tabular}{|c|c|c|c|c|c|c|c|}
\hline & $\begin{array}{l}\text { Variação do } \\
\text { ativo total }\end{array}$ & $\begin{array}{l}\text { Variação do } \\
\text { imobilizado }\end{array}$ & $\begin{array}{c}\text { Variação do } \\
\text { patrimônio líquido }\end{array}$ & $\begin{array}{l}\text { Variação da } \\
\text { receita }\end{array}$ & $\begin{array}{l}\text { Variação do fluxo de } \\
\text { caixa operacional }\end{array}$ & Burocracia & Corrupção \\
\hline Variação do ativo total & 1 & & & & & & \\
\hline Variação do imobilizado & $0,2853 * * *$ & 1 & & & & & \\
\hline Variação do patrimônio líquido & $0,6693 * * *$ & $0,2291 * * *$ & 1 & & & & \\
\hline Variação da receita & $0,5167 * * *$ & $0,2021 * * *$ & $0,3727 * * *$ & 1 & & & \\
\hline Variação do fluxo de caixa operacional & $0,1038 * * *$ & $0,1109^{* * *}$ & $0,0859 * * *$ & $0,0960 * * *$ & 1 & & \\
\hline burocracia & $0,1202 * * *$ & $0,0605 * * *$ & $0,1084 * * *$ & $0,0994 * * *$ & $0,0318^{* *}$ & 1 & \\
\hline corrupção & $0,0840 * * *$ & 0,0118 & $0,0534 * * *$ & $0,0470 * * *$ & 0,0190 & $0,6372 * * *$ & 1 \\
\hline
\end{tabular}

Fonte: Elaborada pelos autores.

$* * * / * * *$ sig. $>=1 \%, 5 \%$ e $10 \%$, respectivamente. Amostra com 665 empresas e 4.648 observações.

Tabela 3. Correlação de Pearson

\begin{tabular}{|c|c|c|c|c|c|c|c|}
\hline & Crescimento & $\begin{array}{l}\text { Vetor comum entre } \\
\text { burocracia e corrupção }\end{array}$ & Receita & $\begin{array}{l}\text { Retorno do } \\
\text { ativo }\end{array}$ & Endividamento & Tamanho & $\begin{array}{l}\text { Crescimento do } \\
\text { PIB per capita }\end{array}$ \\
\hline Crescimento & 1 & & & & & & \\
\hline Vetor comum entre burocracia e corrupção & $0,1146^{* * *}$ & 1 & & & & & \\
\hline Receita & $0,0727 * * *$ & $0,1130^{* * *}$ & 1 & & & & \\
\hline Retorno do ativo & $0,1955^{* * *}$ & $-0,0047$ & $0,0882 * * *$ & 1 & & & \\
\hline Endividamento & $0,0467 * * *$ & $0,0971^{* * *}$ & $0,4381 * * *$ & $-0,1103^{* * *}$ & 1 & & \\
\hline Tamanho & $-0,0776^{* * *}$ & $0,0297 * *$ & $0,8644 * * *$ & $-0,0325^{* *}$ & $0,3478 * * *$ & 1 & \\
\hline Crescimento do PIB per capita & $-0,1418 * * *$ & $-0,2712 * * *$ & $-0,0682 * * *$ & $-0,0003 * * *$ & $-0,1482 * * *$ & $-0,0172 * * *$ & 1 \\
\hline
\end{tabular}

Fonte: Elaborada pelos autores.

Nota: $* * * * * * *$ sig. $>=1 \%, 5 \%$ e 10\%, respectivamente. Amostra com 667 empresas e 4812 observações. 
Depreende-se, pela Tabela 2, que todas as medidas de crescimento consideradas no estudo trazem uma correlação positiva e significativa com a burocracia. Entretanto, com a corrupção, não apresentaram uma correlação significativa a variação do imobilizado e a variação do fluxo de caixa operacional. As demais medidas de crescimento apresentaram uma relação positiva e significativa, ao nível de 1\%, com a corrupção. A maior correlação encontrada foi entre o crescimento dos ativos totais e o crescimento do patrimônio líquido, com 66,93\% de explicação, enquanto, a menor correlação encontrada foi entre a variação dos fluxos de caixa operacional e a variação do patrimônio líquido, com uma explicação de $8,59 \%$.

Verificada a correlação significativa entre as variáveis de crescimento, utilizando a técnica da análise multivariada, foi derivado um fator comum (Crescimento), contemplando as cinco dimensões de crescimento apresentadas na Tabela 2, que foi utilizado como proxy para o crescimento econômico e financeiro das empresas. Conforme o resultado do teste de Kaiser-Meyer-Olkin (KMO), a proporção da variância dos dados considerados comum às cinco dimensões de crescimento considerados no vetor Crescimento foi de 67,37\%. Este resultado indica que a análise fatorial é apropriada, por atingir um índice superior a 0,5.

Ainda na Tabela 2 observa-se que o coeficiente de correlação de Pearson encontrado na amostra, entre o índice de dificuldade de realização de negócios e o índice de percepção de corrupção no setor público, foi de 0,6372, com o nível de significância estatística de 1\%. Com esta alta correlação, reforça-se a perspectiva que a burocracia e a corrupção estão intimamente correlacionadas, favorecendo o cálculo de um vetor comum entre elas, como proxy de sua associação sinérgica.

A variável indicativa do crescimento econômico e financeiro da empresa (Crescimento), utilizada na estimação como variável dependente, apresenta um coeficiente de correlação positivo e significativo no nível de $1 \%$ com a variável derivada do vetor comum entre burocracia e corrupção (FBC), utilizada na estimação como variável de interesse. A variável Crescimento também apresenta coeficiente positivamente significativo com as variáveis de controle Receita, Retorno do Ativo e Endividamento, enquanto as variáveis Tamanho e Crescimento do PIB per capita apresentam correlações negativas e significativas com a variável Crescimento. Com exceção das variáveis Receita e Tamanho, as variáveis de controle e a variável interesse apresentam coeficientes de correlação baixos.

Por conseguinte, para medir a influência da percepção da corrupção no setor público no desempenho econômico nas empresas da amostra, recorreu-se ao modelo econométrico proposto na Equação 1, sendo, incialmente, realizado o teste de Chow, o teste de Hausman e o teste de LM de Breusch-Pagan. Os resultados dos testes apontaram que o modelo estimado com efeitos fixos é mais apropriado.

Com o relaxamento do pressuposto da normalidade na distribuição dos dados, baseando-se no teorema do limite central, foram executados os exames de autocorrelação e homocedasticidade dos dados, não sendo encontrada, pelo teste de Wooldridge, em todos os modelos de desempenho a presença de autocorrelação. Pelo teste de Wald modificado para dados em painel, foi indicado heterocedasticidade dos dados, nos três modelos para estimação da influência da percepção de corrupção no desempenho.

Após todos os testes de pressupostos para estimação das regressões, foram estimadas as regressões utilizando os dados em painel balanceado e desbalanceado, verificando-se que, nas duas formas, os resultados não foram alterados, tampouco houve diminuição na eficiência do estimador. Com isso, o painel desbalanceado foi escolhido, visando ampliar a quantidade de observações, de forma que os resultados obtidos com a estimação do modelo econométrico proposto pela Equação 1 encontra-se na Tabela 4. 
Tabela 4. Estimação da regressão (Efeitos Fixos) da Equação 1

\begin{tabular}{|c|c|c|c|c|c|c|c|}
\hline \multirow{2}{*}{ Variáveis } & \multicolumn{2}{|c|}{ Within variation } & \multicolumn{2}{|c|}{ Between variation } & \multicolumn{2}{|c|}{ General variaton } & \multirow{2}{*}{ VIF } \\
\hline & Coef. & p-valor & Coef. & $\mathrm{p}$-valor & Coef. & p-valor & \\
\hline $\begin{array}{r}\text { Vetor Comum } \\
\text { entre Burocracia e } \\
\text { Corrupção }\end{array}$ & 0,5017 & 0,000 & 0,0667 & 0,006 & 0,0575 & 0,057 & 1.11 \\
\hline Receita & 0,7120 & 0,000 & 0,0781 & 0,000 & 0,4766 & 0,000 & 4.80 \\
\hline Retorno do ativo & 1,6978 & 0,000 & 0,1982 & 0,490 & 1,7575 & 0,000 & 1.10 \\
\hline Endividamento & 0,7824 & 0,000 & $-0,1591$ & 0,199 & 0,1791 & 0,233 & 1,31 \\
\hline Tamanho & -1.1687 & 0,000 & $-0,0863$ & 0,000 & $-0,5923$ & 0,000 & 4.29 \\
\hline \multirow{7}{*}{$\begin{array}{r}\text { Crescimento do PIB } \\
\text { per capita } \\
\text { Intercepto }\end{array}$} & $-0,0166$ & 0,000 & $-0,0673$ & 0,000 & $-0,0289$ & 0.000 & 1.10 \\
\hline & 9.0974 & 0,000 & 0,3988 & 0,048 & 2,4997 & 0,000 & \\
\hline & \multicolumn{2}{|c|}{ within $=0,3917$} & \multicolumn{2}{|c|}{ within $=0,0677$} & \multicolumn{2}{|c|}{ Parâmetro de escala } & Obs. $=4.648$ \\
\hline & \multicolumn{2}{|c|}{ between $=0,0640$} & \multicolumn{2}{|c|}{ between $=0,1220$} & \multicolumn{2}{|c|}{1.038452} & Grupos $=655$ \\
\hline & \multicolumn{2}{|c|}{ general $=0,0787$} & \multicolumn{2}{|c|}{ general $=0,0617$} & \multicolumn{2}{|c|}{ Wald chi2 $(6)=208,29$} & \\
\hline & \multicolumn{2}{|c|}{$F(6,654)=78,69$} & \multicolumn{2}{|c|}{$F(6,648)=15,01$} & \multicolumn{2}{|c|}{ Prob $>$ chi $2=0,0000$} & \\
\hline & \multicolumn{2}{|c|}{ Prob $>F=0,0000$} & \multicolumn{2}{|c|}{ Prob $>F=0,0000$} & \multicolumn{2}{|c|}{ Prob $>F=0,0000$} & \\
\hline
\end{tabular}

Fonte: Elaborada pelos autores.

Nota: Crescimento $=$ crescimento econômico da empresa $i$ do período $t-1$ a $t$. Vetor Comum entre Burocracia e Corrupção $=$ vetor comum do crescimento econômico ao índice de dificuldade de realização de negócios e ao índice de percepção da corrupção no setor público; Receita $=\log$ da receita líquida da empresa $i$ no período $t$; Retorno do Ativo $=$ retorno sobre o ativo da empresa $i$ no período $t$; Endividamento $=$ endividamento da empresa $i$ no período $t$; Tamanho $=\log$ natural do ativo total da empresa $i$ no período $t-1$; e Crescimento do PIB per capita $=$ crescimento anual do Produto Interno Bruto per capita anual do país no período $t-1$.

Nos três modelos regressivos de efeitos fixos estimados (within, between e general variation), os resultados se mantiveram persistentes. Todavia, o modelo de efeitos fixos within foi escolhido, porque esse modelo tem a capacidade de capturar a heterocedasticidade interna de cada indivíduo, para cada período de tempo. Assim, levando em consideração que o problema de pesquisa visou analisar, especificamente, o efeito da associação entre a dificuldade de realização de negócios e a percepção de corrupção sobre o crescimento econômico nas empresas do Mercosul, utilizou-se o modelo de efeitos fixos within variation pela importância da heterogeneidade de cada empresa para o estudo.

Desse modo, depreende-se pelas informações constante na Tabela 4 que, em média, a associação entre a dificuldade de realização de negócios e a percepção de corrupção no setor público exerce uma influência direta e significativa, ao nível de 1\%, na magnitude de 50,17\% no crescimento das empresas (Crescimento) no Mercosul. Este resultado coaduna-se com a Teoria da Graxa sobre Rodas e com os resultados dos estudos de Aidt (2003), Vial e Hanoteau (2010), Dreher e Gassebner (2013) e Kato e Sato (2015). Aqui, o reflexo positivo da sinergia entre burocracia e corrupção sobre o crescimento das empresas no Mercosul pode ir além da corrupção como "graxa" sobre as "engrenagens" em ambientes burocráticos: poderia decorrer da ineficiência da burocracia.

Tal resultado sugere que a corrupção pode estar sendo ampliada pelo ambiente burocrático do país, mediante a sinergia identificada entre eles. A burocracia dificulta a realização das atividades econômicas das empresas, impondo processos e excesso de regras e normas que podem comprometer a execução da atividade econômica e, consequentemente, o crescimento das empresas sujeitas a tais regramentos. Em um ambiente com esse desenho, a corrupção encontra um terreno mais fértil para se proliferar e amenizar ou desatar as amarras da burocracia. Vale salientar que a corrupção não é uma solução para a burocracia, mas que a redução da burocracia pode ser um desestímulo à corrupção.

De acordo com Tabela 4, todas as variáveis de controle se mostram significativas no nível de $1 \%$ de significância com o crescimento econômico da empresa. Os resultados obtidos indicam que as variáveis Receita, Retorno do ativo e Endividamento refletem positivamente no crescimento econômico e financeiro das empresas. Com relação à receita, verificou-se, na amostra, que a sua elevação pode determinar um crescimento no desempenho econômico e financeiro nas empresas. Tal fato ocorre, possivelmente, porque um aumento no montante das vendas pode gerar um aumento de produção e, por consequência, um ganho de escala, com redução de custos e elevação da margem de contribuição dos produtos e serviços vendidos. 
No tocante ao retorno dos ativos, maiores retornos sobre o investimento podem induzir o investimento e ampliação das atividades das empresas, ocasionado o seu crescimento econômico e financeiro. Já para o endividamento, as empresas mais alavancadas conseguem crescer mais em virtude dos recursos advindos de terceiros que financiarem os seus projetos.

Os resultados indicam uma relação negativa, com significância estatística ao nível de 1\%, entre o PIB per capita e o crescimento financeiro e econômico das empresas. Este resultado sugere a existência de um ciclo econômico onde, o volume da riqueza circulada em períodos passados na economia de um país por habitante, ciclicamente reduz o crescimento econômico e financeiro das empresas em períodos posteriores. Sendo que, os ciclos econômicos são decorrentes das flutuações do nível de atividade econômica de um país, geralmente mensurado pelo PIB.

Quanto à variável Tamanho, esta apresentou uma relação negativa, significativa ao nível de 1\%, com o crescimento econômico e financeiro das empresas. Isso pode decorrer do fato de que empresas menores, em medidas de resultados econômicos e financeiros, cresçam mais, proporcionalmente, que empresas maiores, por apresentarem maiores perspectivas de crescimento, gerando uma relação inversa entre tamanho e crescimento econômico e financeiro.

\section{CONSIDERAÇÕES FINAIS}

Baseando-se na Teoria da Graxa sobre as Rodas, a pesquisa levou em consideração que a sinergia entre a corrupção e a burocracia poderia favorecer o crescimento econômico das empresas pelo ganho de competividade no mercado, ao reduzir os custos transacionais das empresas com cumprimento de exigências normativas. Assim, este artigo contribui para o aprofundamento da discussão sobre a sinergia entre a corrupção e a burocracia.

Os achados sugerem que a redução ou elevação da sinergia entre o índice dificuldade de realização de negócios e o índice de percepção de corrução do país reflete diretamente no crescimento das empresas atuantes nesse ambiente econômico. Apesar de a corrupção provocar efeitos nocivos à sociedade e ao ambiente como um todo, além de danos à imagem da empresa e falta de credibilidade, que podem refletir negativamente no retorno da empresa, o excesso de burocracia pode impor restrições ainda maiores ao crescimento econômico das empresas. Além disso, em um contexto mais amplo, a redução da burocracia pode vir a aumentar a competitividade das empresas, visto que, as empresas menores também se beneficiariam da redução de processos burocráticos.

A corrupção, em parte, pode ser entendida como um fator agregado à ineficiência decorrente do excesso de burocracia. Esta, por vez é imposta como mecanismo para controlar a corrupção, principalmente, quando envolve operação com agentes públicos, e a corrupção pode ser um estimulante para dar agilidade as transações econômicas. A celeridade nas transações entre os agentes pode representar uma redução nos custos de transações resultantes da burocracia, mas pode também ocasionar outros custos de transações atrelados à manutenção da relação com agentes corruptos.

A corrupção não é uma solução para os problemas decorrentes do excesso de burocracia, mas ela pode ser um fator agregado ao processo demasiadamente burocrático. Portanto, em tese, enfrentar a excessiva burocracia com processos mais dinâmicos poderia levar a redução da corrupção, pois é possível que a corrupção se alimente da burocracia, de forma que a criação de dificuldade (burocracia) ocasione a demanda pela oferta de facilidade (corrupção).

As evidências empíricas encontradas acrescentam novos argumentos para o constructo argumentativo no qual se pauta a Teoria da Graxa sobre Rodas, fomentando fortes embates éticos e impondo uma ampla discussão sobre as políticas públicas de combate à corrupção no mundo e seu prejuízo para a sociedade, de forma sistêmica, sendo possível que atinja outros países ou blocos econômicos além do Mercosul.

Isto posto, esta pesquisa traz como contribuição, com base na interseção entre a Teoria da Graxa sobre Rodas e a Teoria do Custo de Transação, a revelação que a corrupção em ambientes altamente burocráticos pode contribuir positivamente para o crescimento das empresas. Deste modo, amplia-se os limites dos estudos relacionados ao comportamento organizacional, ligados ao desempenho econômico, para apresentar explicações mais amplas sobre o ambiente empresarial nos blocos econômicos compostos por países em desenvolvimento diante da corrupção. Por fim, sugere-se que pesquisas futuras explorem o feito da sinergia entre corrupção e burocracia em empresas de diferentes tamanhos e ambientes competitivos. 


\section{REFERÊNCIAS}

Aidt, T. (2003). Economic analysis of corruption: A survey. Economic Jornal, 113(491), 632-652. DOI: https:// doi.org/10.1046/j.0013-0133.2003.00171.x.

Antunes, M. A., \& Procianoy, J. L. (2003). Os efeitos das decisões de investimentos das empresas sobre o preço de suas ações no mercado de capitais. Rausp, 38, 5-14. Disponível em: http://rausp.usp.br/wp-content/uploads/ files/V3801005.pdf.

Coase, R. H. (1937). The nature of the firm. Economica, 4(16), 386-405. DOI: https://doi. org/10.1111/j.1468-0335.1937.tb00002.x

Doing Business - Banco Mundial. Disponível em: <http://www.doingbusines.org>. Acesso em: out. 2018.

Dreher, A., \& Gassebner, M. (2013). Greasing the wheels? The impact of regulations and corruption on firm entry. Public Choice, 155, 413-432. DOI: https://doi.org/10.1007/s11127-011-9871-2.

Fama, E. F., \& French, K. R. (2006). Profitability, investment and average returns. Journal of Financial Economics, 82(3), 491-518. DOI: https://doi.org/10.1016/j.jfineco.2005.09.009.

Fávero, L. P. (2013). Dados em painel em contabilidade e finanças: teoria e aplicação. BBR-Brazilian Business Review, 10(1), 131-156. DOI: https://doi.org/10.15728/bbr.2013.10.1.6.

Feldkircher, M. (2014). The determinants of vulnerability to the global financial crisis 2008 to 2009: Credit growth and other sources of risk. Journal of international Money and Finance, 43, 19-49. DOI: https://doi. org/10.1016/j.jimonfin.2013.12.003.

Fortunato, G., Funchal, B., \& Motta, A. P. (2012). Impacto dos Investimentos no Desempenho das Empresas Brasileiras. Revista de Administração Mackenzie, 13(4), 75-98. Disponível em: https://www.redalyc.org/ pdf/1954/195423696004.pdf.

Goedhuys, M., Mohnen, P., \& Taha, T. (2016). Corruption, innovation and firm growth: firm-level evidence from Egypt and Tunisia. Eurasian Business Review, 6(3), 299-322. DOI: https://doi.org/10.1007/s40821-0160062-4.

Kato, A., \& Sato, T. (2015). Greasing the wheels? The effect of corruption. Canadian Journal of Development Studies, 36(4), 459-483. DOI: https://doi.org/10.1080/02255189.2015.1026312.

Lau, C., Demir, E., \& Bilgin, M. (2013). Experience-based corporate corruption and stock market volatility: Evidence from emerging markets. Emerging Markets Review, 17, 1-13. DOI: https://doi.org/10.1016/j. ememar.2013.07.002.

Lopes Júnior, E., Cãmara, S., Rocha, L., \& Brasil, A. (2018). Influência da Corrupção nos Gastos das Empresas Estatais. Revista de Administração Pública, 52(4), 695-711. Disponível em: http://bibliotecadigital.fgv.br/ ojs/index.php/rap/article/view/75721.

Méon, P., \& Weill , L. (2010). Is Corruption an Efficient Grease? World Development, 38(3), 244-259. DOI: https://doi.org/10.1016/j.worlddev.2009.06.004.

Rock, M., \& Bonnett, H. (2004). The comparative politics of corruption: Accounting for the East Asian paradox in empirical studies of corruption,growth and investment. World Development, 32(6), 999-1017. DOI: https:// doi.org/10.1016/j.worlddev.2003.12.002.

Silva, A. M., Braga, E. C., \& Laurencel, L. C. (2009). A Corrupção em uma Abordagem Econômico-Contábil e o Auxílio da Auditoria como Ferramenta de Combate. Contabilidade Vista \& Revista, 20(1), 95-117. Disponível em: https://revistas.face.ufmg.br/index.php/contabilidadevistaerevista/article/view/575/389.

Transparency International. (2018). Corruption Perception Index 2018. Disponível em: www.transparency.org.

Vial, V., \& Hanoteau, J. (2010). Corruption, manufacturing plant growth, and the Asian paradox: Indonesian evidence. World Development, 38(5), 693-705. DOI: https://doi.org/10.1016/j.worlddev.2009.11.022.

Vu, H., Tran, T., Nguyen, T., \& Lim, S. (2018). Corruption, Types of Corruption and Firm Financial Performance: New Evidence from a Transitional Economy. Journal of Business Ethics, 148(4), 847-858. DOI: https://doi. org/10.1007/s10551-016-3016-y.

Williamson, O. E. (1973). Markets and hierarchies: Some Elementary Considerations. The American Economic Review, 63(2), 316-325. Disponível em: https://www.jstor.org/stable/1817092. 